\title{
Evaluation of the posterior superior alveolar artery and the maxillary sinus with CBCT
}

\section{Dilhan Ilgüy \\ Mehmet Ilgüy \\ Semanur Dolekoglu \\ Erdogan Fisekcioglu}

Department of Dentomaxillofacial Radiology, Faculty of Dentistry, Yeditepe University, Istanbul, Turkey.
Declaration of Interests: The authors certify that they have no commercial or associative interest that represents a conflict of interest in connection with the manuscript.

Corresponding Author:

Dilhan llgüy

E-mail: dilhan.ilguy@yeditepe.edu.tr

Submitted: Mar 20, 2013

Accepted for publication: Jul 02, 2013

Last revision: Jul 17, 2013
Abstract: Assessment of the maxillary sinus anatomy before sinus augmentation is important for avoiding surgical complications, because of the close anatomical relationship between the posterior maxillary teeth and the maxillary sinus. The posterior superior alveolar artery (PSAA) is the branch of the maxillary artery that supplies the lateral sinus wall and overlying membrane. We evaluated the location of the PSAA and its relationship to the alveolar ridge and maxillary sinus using cone beam computed tomography (CBCT). The study group consisted of 135 CBCT scans (270 sinuses) obtained from the archive of the dentomaxillofacial radiology department at Yeditepe University Faculty of Dentistry, Istanbul, Turkey. The distance between the lower border of the artery and the alveolar crest, bone height from the sinus floor to the ridge crest, distance from the artery to the medial sinus wall, and the diameter and location of the artery were determined. The occurrence of septa and pathology were recorded from CBCT scans. The PSAA was observed in $89.3 \%$ of sinuses, and $71.1 \%$ of arteries were intraosseous with diameters mostly $\leq 1 \mathrm{~mm}$ (68.9\%). The prevalence of sinus septa was $55.2 \%$, and that of sinus pathology was $57.4 \%$. The mean age was $43.07 \pm 17.55$ years. There was a statistically significant difference between the location of the artery and gender $(\mathrm{p}<0.05)$. The prevalence of sinus membrane thickening was $57.4 \%$. Detailed knowledge about the location of the PSAA and sinus morphology may be obtained with CBCT before maxillary sinus surgery.

Descriptors: Maxillary Artery; Maxillary Sinus; Cone-Beam Computed Tomography.

\section{Introduction}

The posterior superior alveolar artery (PSAA) and infraorbital artery (IOA) are the branches of the maxillary artery that supply the lateral sinus wall and overlying membrane. The blood supply of the maxillary sinus and Schneiderian membrane comes from the maxillary artery. ${ }^{1,2}$ Sinus augmentation is a safe procedure with high predictability for rehabilitation of severely atrophic posterior maxillae. ${ }^{3-6}$ The branches of the maxillary artery should be taken into consideration during sinus augmentation because of the potential risk of bleeding during the procedure owing to damage to the vascular supply in the lateral wall. ${ }^{7}$ Assessment of the maxillary sinus anatomy is important to avoid unnecessary complications due to the close anatomical relationship of the PSAA with the 


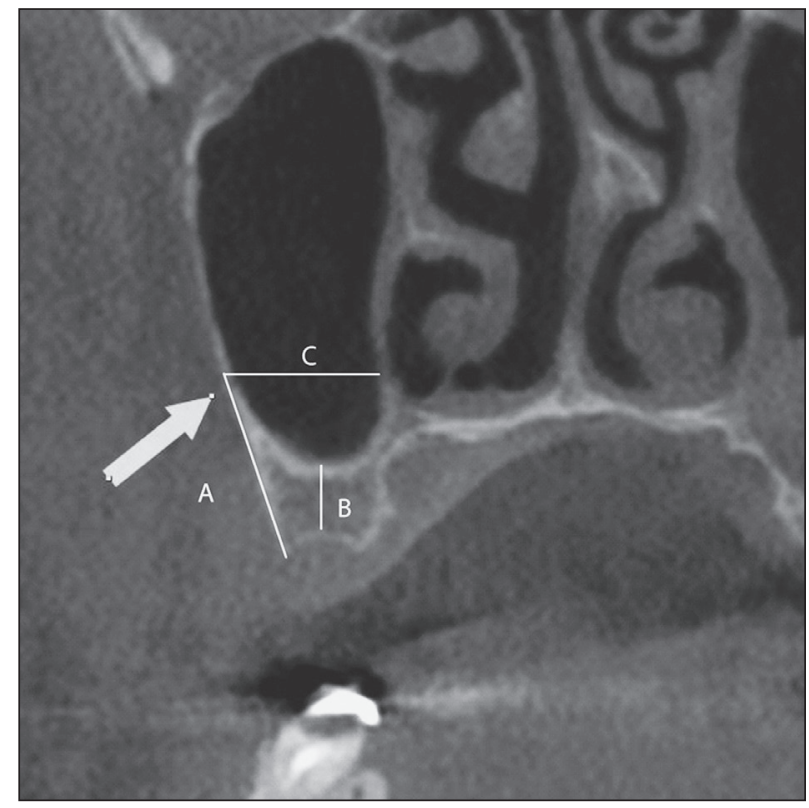

Figure 1- Distance between the lower border of the artery and the alveolar crest $(\mathbf{A})$, bone height from the sinus floor to the ridge crest (B), and distance from the artery to the medial sinus wall $(\mathbf{C})$.

maxillary sinus. ${ }^{8,9}$

Any imaging technique that subjects the patient to ionizing radiation must yield as much pertinent information as possible, and it is important that the physician collect all the useful information possible. Cone beam computed tomography (CBCT) may be recommended as a dose-sparing technique compared with standard medical computed tomography (MDCT) scans for dentomaxillofacial imaging. Increases in $\mathrm{kV}, \mathrm{mA}$, exposure time, and field of view increase the radiation dose regardless of the type of imaging technique used. ${ }^{10}$ The effective dose (International Commission on Radiological Protection - ICRP 2007) from a standard dental protocol scan with MDCT is 1.5 to 12.3 times greater than from comparable medium-field of view dental CBCT scans. ${ }^{11,12}$ Thus, CBCT is frequently used for preoperative assessment of the alveolar ridge and maxillary sinus in patients receiving implants in the posterior maxilla.

The purpose of this study was to evaluate the location of the PSAA and its relationship to the alveolar ridge and maxillary sinus using CBCT.

\section{Methodology}

The study design underwent formal review and received approval from the institutional review board of our institution. The retrospective study group was planned according to Sample Size Estimation Simple Random Sampling and consisted of 135 CBCT scans of 55 males and 80 females $(270$ sinuses) obtained from the archive of the Dentomaxillofacial Radiology Department of the faculty. Patient ages ranged from 18 to 83 years. Digital images were taken using an Iluma CBCT scanner (Imtec Corporation, Oberursel, Germany) with an amorphous silicon flat-panel image detector and a cylindrical volume of reconstruction of up to $19 \times$ $24 \mathrm{~cm}$. Images were taken at $120 \mathrm{kVp}, 3.8 \mathrm{~mA}$, and a voxel size of $0.2 \mathrm{~mm}$, with an exposure time of 40 seconds. 3D reconstructions were created by reformatting the axial CBCT scans on a local workstation using Iluma dental imaging software (Imtec Corporation). A written informed consent form, which is routinely obtained from each patient prior to imaging in our faculty, also included a clause for the use of images in this research. Before measurements were made, the orientation of the images was determined for each patient.

On coronal scans, evaluation was made between where the artery was first and last seen. The distance between the lower border of the artery and the alveolar crest (A), bone height from the sinus floor to the ridge crest (B), distance from the artery to the medial sinus wall $(\mathrm{C})$, and the diameter and location of the artery were determined (Figure 1); occurrence of sinus septa and membrane thickening were also recorded from CBCT scans. Locations of the artery were:

a. intraosseous (Figure 2),

b. below the membrane (Figure 3), and

c. on the outer cortex of the lateral sinus wall (Figure 4).

$\mathrm{A}$ and $\mathrm{B}$ were calculated for only the edentulous alveolar crest.

A dentomaxillofacial radiology specialist evaluated the images in a darkened quiet room with dual monitors (HP LP2475W, resolution $1920 \times 1200$; Hewlett-Packard, Houston, USA). Each viewing ses- 


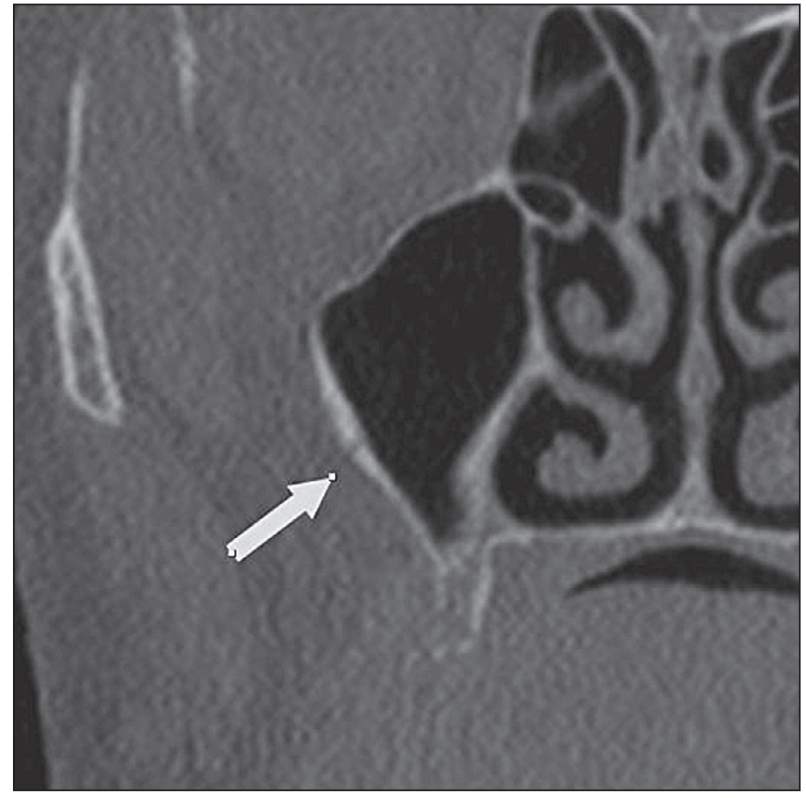

Figure 2 - Coronal view of the maxillary sinus reveals the intraosseous artery (arrow).

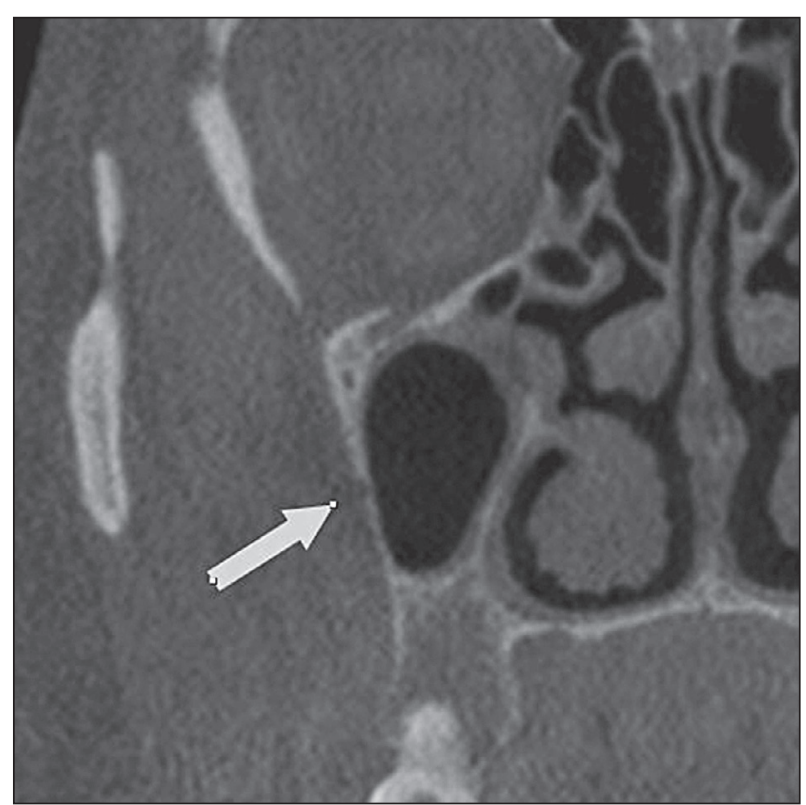

Figure 4 - Coronal view of the maxillary sinus reveals the artery (arrow), which is on the outer cortex of the lateral sinus wall.

sion lasted 30 minutes. Care was taken to ensure that 24 hours elapsed between all sessions. For intra-examiner calibration and determination of reliability and reproducibility of the measurements, the images were evaluated a second time by the same observer 2 weeks later.

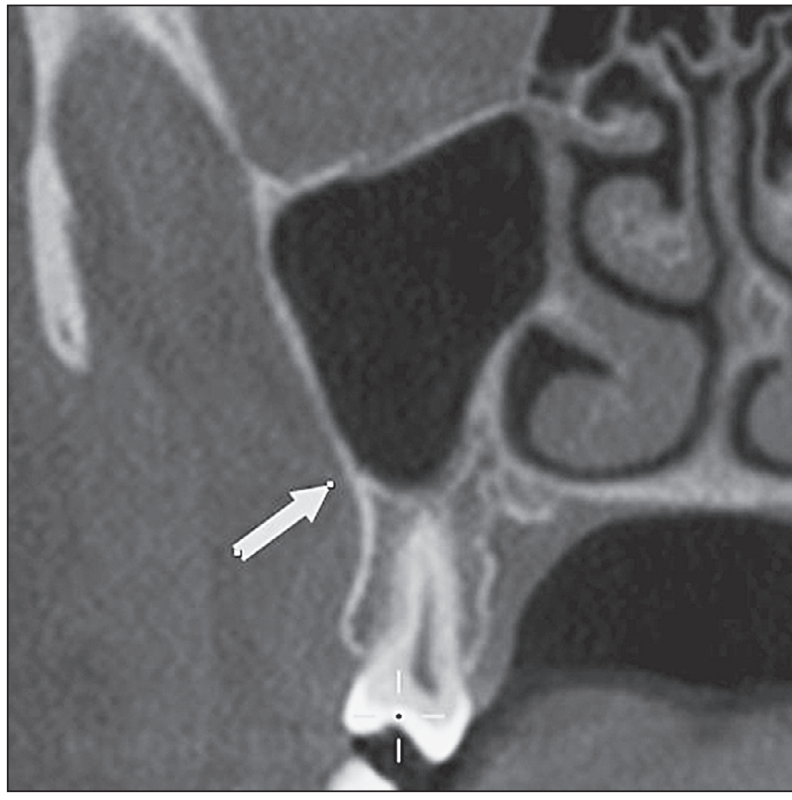

Figure 3 - Coronal view of the maxillary sinus reveals the artery (arrow), which is below the membrane.

SPSS 15.0 (Statistical Package for Social Sciences, IBM, New York, USA) for Windows 2007 (Microsoft, New Mexico, USA) was used for statistical analysis of the results. Prior to the study, all parameters were evaluated with the Kolmogorov-Smirnov test, and the data were found to be normally distributed. Simple Random Sampling Sample Size Estimation was done. While evaluating the data using descriptive statistical methods, parameters with normal distribution for the comparison of quantitative data were evaluated using one-way analysis of variance, the Tukey test, and Student's t-test. Qualitative data were evaluated using the Chi-square test. The Pearson correlation was used to assess potential correlations between parameters. Intra-observer agreement was calculated using the intraclass correlation coefficient. Significance was accepted at $p<0.05$.

\section{Results}

The mean age of the study participants was $43.07 \pm 17.55$ years. The intraclass correlation coefficient results reflect the intra-observer reliability, which is a measure of whether the observer assigned similar ratings with repeated observations for each measurement. Intraclass correlation coefficient 
Table 1 - Artery localization according to age, gender, and edentulous/dentulous alveolar crest.

\begin{tabular}{|c|c|c|c|c|c|c|}
\hline & & Absence & Intraosseous & $\begin{array}{l}\text { Below the } \\
\text { membrane }\end{array}$ & $\begin{array}{l}\text { On the outer cortex of } \\
\text { the lateral sinus wall }\end{array}$ & \multirow[t]{2}{*}{$p$ value } \\
\hline & & n (\%) & n (\%) & n (\%) & n (\%) & \\
\hline \multirow{5}{*}{$\begin{array}{c}\text { Age } \\
\text { (years) }\end{array}$} & $20-29$ & $7 \quad(9.0)$ & $55(70.5)$ & 11 (14.1) & $5 \quad(6.4)$ & \multirow{5}{*}{0.129} \\
\hline & $30-39$ & $1 \quad(2.8)$ & 30 (83.3) & $4(11.1)$ & 1 (2.8) & \\
\hline & $40-49$ & $2 \quad(5.9)$ & 29 (85.3) & $3 \quad(8.8)$ & $0 \quad(0.0)$ & \\
\hline & $50-59$ & $13(17.6)$ & $43(58.1)$ & 14 (18.9) & $4 \quad(5.4)$ & \\
\hline & $\geq 60$ & $6(12.5)$ & 35 (72.9) & 3 (6.3) & $4 \quad(8.3)$ & \\
\hline \multirow{2}{*}{ Gender } & Female & 17 (10.6) & 119 (74.4) & $21(13.1)$ & 3 (1.9) & \multirow{2}{*}{$0.03^{*}$} \\
\hline & Male & $12(10.9)$ & $73(66.4)$ & 14 (12.7) & 11 (10.0) & \\
\hline \multicolumn{2}{|c|}{ Edentulous } & $28(24.1)$ & $68(58.6)$ & 12 (10.3) & 8 (6.9) & \multirow{2}{*}{$0.00^{* *}$} \\
\hline \multicolumn{2}{|c|}{ Dentulous } & $1 \quad(0.6)$ & $124(80.5)$ & 23 (14.9) & 6 (3.9) & \\
\hline
\end{tabular}

${ }^{*} p<0.05 ;{ }^{* *} p<0.01$ (chi-square test).

scores of measurements A, B, and C were 0.95, 0.98, and 0.97 , respectively. Kappa values for the diameter and location of the artery were $81.5 \%$ and $98 \%$, respectively, and for the occurrence of septa and pathology they were $86.5 \%$ and $93 \%$, respectively.

The PSAA was observed in $89.3 \%$ of all sinuses; $71.1 \%$ of arteries were intraosseous, $13 \%$ were below the membrane, and only $5.2 \%$ were on the outer cortex of the lateral sinus wall. The artery diameters ranged from 0.4 to $1.7 \mathrm{~mm}$ with a mean value of $0.94 \pm 0.26 \mathrm{~mm}$. The artery diameters were mostly $\leq 1 \mathrm{~mm}(68.9 \%)$. The percentages of artery diameters $\leq 1 \mathrm{~mm}$ were $73.5 \%$ and $64.5 \%$ for the right and left sinuses, respectively, a difference that was not statistically significant $(p>0.05)$. More males $(39.8 \%)$ than females $(25.2 \%$; $p<0.05)$ had an artery diameter of 1 to $2 \mathrm{~mm}$. No significant correlation was found between the presence of the artery and age/gender $(p>0.05)$. A statistically significant difference was found between locations of the artery and gender $(p<0.05)$. Although the prevalence of an intraosseous PSAA was significantly higher in females $(74.4 \%)$ than males $(66.4 \%)$, the PSAA was located on the outer cortex of the lateral sinus wall in males $(10 \%)$ significantly more often than in females (1.9\%; Table $1 ; p<0.05)$.

Regarding the prevalence of the artery, there was a statistically significant difference between edentulous and dentulous alveolar crest where the artery was identified. The artery was observed less often
Table 2 - Measurements according to gender.

\begin{tabular}{l|r|r|c}
\hline & \multicolumn{1}{|c|}{ Female } & \multicolumn{1}{c|}{ Male } & \multirow{2}{*}{ p value } \\
\cline { 2 - 3 } & \multicolumn{1}{c|}{ Mean \pm SD } & \multicolumn{1}{c}{ Mean \pm SD } & \\
\hline$A^{* *}$ & $16.79 \pm 3.79$ & $17.00 \pm 2.94$ & 0.785 \\
\hline$B^{* * *}$ & $7.50 \pm 3.03$ & $8.34 \pm 3.43$ & 0.233 \\
\hline$C^{* * * *}$ & $13.27 \pm 2.82$ & $14.03 \pm 2.44$ & $0.031^{*}$ \\
\hline
\end{tabular}

${ }^{*} p<0.05$ (Student's $\dagger$ test). ${ }^{* *}$ Distance between the lower border of the artery and the alveolar crest. ${ }^{* * *}$ Bone height from the sinus floor to the ridge crest. ${ }^{* * * *}$ Distance from the artery to the medial sinus wall.

in the edentulous crest $(75.9 \%)$ than dentulous crest (99.4\%; $p<0.01)$. No statistically significant difference was observed between gender and distance from the artery to the alveolar crest $(p>0.05$; Table $2)$. The distance from the artery to the medial sinus wall in males was significantly higher than in females $(p<0.05)$. With regard to the edentulous crest, the mean distance from the artery to the alveolar crest was $16.88 \pm 3.46 \mathrm{~mm}(\mathrm{~A})$, and the bone height from the sinus floor to the ridge crest (B) was $7.84 \pm 3.20 \mathrm{~mm}$. The mean distance from the artery to the medial sinus wall $(\mathrm{C})$ in dentulous crests $(13.92 \pm 2.84 \mathrm{~mm})$ was significantly higher than that measured for the edentulous crest $(13.00 \pm 2.32 \mathrm{~mm} ; p<0.05)$. There also was a statistically significant difference among age groups regarding the distance from the artery to the medial sinus wall ( $p<0.01$; Table 3$)$. According to the Pearson correlation test, a negative $(-20.1 \%)$ correlation 
Table 3 - Measurements according to age groups.

\begin{tabular}{|c|c|c|c|c|c|c|}
\hline & 20-29 & 30-39 & $40-49$ & 50-59 & $\geq 60$ years & \multirow{2}{*}{$p$ value } \\
\hline & Mean \pm SD & Mean \pm SD & Mean \pm SD & Mean \pm SD & Mean \pm SD & \\
\hline$A^{* *}$ & $17.01 \pm 3.01$ & $17.52 \pm 4.18$ & $17.05 \pm 2.93$ & $15.97 \pm 3.42$ & $17.40 \pm 3.54$ & 0.553 \\
\hline $\mathrm{B}^{* * *}$ & $8.29 \pm 3.20$ & $9.62 \pm 3.28$ & $7.74 \pm 1.70$ & $7.65 \pm 3.76$ & $7.50 \pm 2.92$ & 0.546 \\
\hline$C^{* * * *}$ & $14.18 \pm 2.48$ & $14.89 \pm 2.40$ & $13.00 \pm 2.27$ & $12.60 \pm 3.05$ & $13.34 \pm 2.45$ & $0.001^{*}$ \\
\hline
\end{tabular}

${ }^{*} p<0.01$ (one-way analysis of variance). ${ }^{* *}$ Distance between the lower border of the artery and the alveolar crest. ${ }^{* * *}$ Bone height from the sinus floor to the ridge crest. ${ }^{* * * *}$ Distance from the artery to the medial sinus wall.

was found between these two parameters $(p<0.01)$. Increased age was negatively associated with the distance between the artery and the medial sinus wall. In other words, older participants tended to have a shorter distance between their artery and the medial sinus wall. The prevalence of sinus septa was $55.2 \%$ and that of sinus membrane thickening was $57.4 \%$. The presence of pathology in men $(68.2 \%)$ was significantly higher than in females $(48.8 \% ; p<0.01)$.

\section{Discussion}

Sinus augmentation is a method with high predictability for placing successful dental implants into atrophic posterior maxillae. ${ }^{3-6}$ Knowledge of the anatomic structure of the area is important for this procedure. In the present study, we were able to observe the presence and location of the PSAA with CBCT scans. The artery was observed in $89.3 \%$ of the sinuses and was mostly intraosseous (71.1\%). The success rate for identifying the artery was higher than that reported by Güncü et al. ${ }^{13}(64.5 \%)$, Elian et al. ${ }^{14}(52.9 \%)$, Mardinger et al. ${ }^{15}$ (55\%), and Kim et al. ${ }^{16}(52 \%)$. This may be related to the methods the other groups used to detect and describe the artery. Collectively, these results suggest that an undetected intrabony canal in a CT scan does not exclude its existence but that it may not be visible owing to its small diameter. ${ }^{15} \mathrm{CBCT}$ provides accurate and reliable linear measurements for reconstruction and imaging of dental and maxillofacial structures.-9

According to Kim et al. ${ }^{16}$ the prevalence of the PSAA differs significantly between males (64\%) and females $(40 \%)$. In the present study, no significant correlation was found between gender and presence of the artery. The reason may be that the number of males/females differs between the two studies.

Table 2 shows that the mean distance of the ar- tery from the alveolar ridge was $16.79 \pm 3.79 \mathrm{~mm}$ for females and $17.00 \pm 2.94 \mathrm{~mm}$ for males. In anatomic studies, this distance was reported to be 18.9-19.6 mm. ${ }^{1,2}$ We observed a shorter distance than in these anatomic studies. The differences may be due to the small number of cases evaluated with CT in previous studies as reported by Güncü et al. ${ }^{13}$ $(18 \mathrm{~mm})$, Elian et al. ${ }^{14}(16.4 \mathrm{~mm})$, Mardinger et al..$^{15}$ (16.9 mm), and Kim et al. ${ }^{16}$ (18.9 mm). Our current results are close to those of these studies.

In the present study, the mean distance from the artery to the crest was $7.50 \pm 3.03 \mathrm{~mm}$ in females and $8.34 \pm 3.43 \mathrm{~mm}$ in males. The mean distance from the artery to the antral floor was $9.29 \mathrm{~mm}$ in females and $8.66 \mathrm{~mm}$ in males. This distance reported by Güncü et al. ${ }^{13}$ was $7.8 \pm 0.3 \mathrm{~mm}$ and by Mardinger et al. ${ }^{15}$ was 7-8 $\mathrm{mm}$. These differences may be explained by the anatomic variation in the positions of arteries.

Damage to the bony vessel can cause bleeding, may obscure the physician's line of sight, and may lead to perforation of the Schneiderian membrane, all of which prolong the operation and assessment of the sinus membrane reflection. ${ }^{17}$ According to our current results, the mean artery diameter was $0.94 \pm 0.26 \mathrm{~mm}$. However, Güncü et al. ${ }^{13}$ Ella et al., ${ }^{7}$ and Kim et al. ${ }^{16}$ reported larger diameters of $1.3 \mathrm{~mm}, 1.2 \mathrm{~mm}$, and $1.52 \mathrm{~mm}$, respectively. Similarly, in anatomic studies, the diameter was reported to be $1.6 \mathrm{~mm}$ at the exit from the maxillary artery. ${ }^{1,2}$

In our study group, artery diameter was generally $\leq 1 \mathrm{~mm}$ (68.9\%). Güncü et al. ${ }^{13}$ reported that only $36.1 \%$ of arteries were $\leq 1 \mathrm{~mm}$, Mardinger et al..$^{15}$ reported that $26 \%$ of sinuses have vessels $\leq 1 \mathrm{~mm}$, and Kim et al. ${ }^{16}$ detected $13.9 \%$ of vessels with diameters $<1 \mathrm{~mm}$. We found that the artery was $\geq 1 \mathrm{~mm}$ in $31.1 \%$ of patients, which may suggest that the in- 
cidence of intense bleeding during a sinus augmentation is low.

In our study group, the average diameter of arteries was higher in males $(39.8 \%)$ than females (25.2\%). Although Güncü et al. ${ }^{13}$ and Kim et al. ${ }^{16}$ reported similar results, Mardinger et al. ${ }^{15}$ found no difference between men and women regarding the diameter of the artery. Anatomic variations in the maxillary sinus may be important for dental implant planning. In some instances, dental implant planning may require modifications related to sinus morphology. Results from our present study revealed that sinus septa were observed in $55.2 \%$ of the 270 sinuses. The prevalence of sinus septa found by Güncü et al..$^{13}$ was $16.1 \%$, by Krennmair et al..$^{18}$ was $16 \%$, and by Kim et al. ${ }^{19}$ was $26.5 \%$ when CT was used to assess the sinuses. These results are not consistent with those of the present study. On the other hand, much higher percentages have been reported with CBCT, and they are close to the results obtained in our present study. Orhan et al. ${ }^{20}$ report-

\section{References}

1. Solar P, Geyerhofer U, Traxler H, Windisch A, Ulm C, Watzek G. Blood supply to the maxillary sinus relevant to sinus floor elevation procedures. Clin Oral Implants Res. 1999 Feb;10(1):34-44.

2. Traxler H, Windisch A, Geyerhofer U, Surd R, Solar P, Firbas W. Arterial blood supply of the maxillary sinus. Clin Anat. 1999;12(6):417-21.

3. Wallace SS, Froum SJ. Effect of maxillary sinus augmentation on the survival of endosseous dental implants A systematic review. Ann Periodontol. 2003 Dec;8(1):328-43.

4. Aghaloo TL, Moy PK. Which hard tissue augmentation techniques are the most successful in furnishing bony support for implant placement?. Int J Oral Maxillofac Implants. 2007;22 Suppl:49-70

5. Del Fabbro M, Rosano G, Taschieri S. Implant survival rates after maxillary sinus augmentation. Eur J Oral Sci. 2008 Dec;116(6):497-506. DOI: 10.1111/j.16000722.2008.00571.x.

6. Pjetursson BE, Tan WC, Zwahlen M, Lang NP. A systematic review of the success of sinus floor elevation and survival of implants inserted in combination with sinus floor elevation. J Clin Periodontol. 2008 Sep;35(8 Suppl):216-40. DOI: 10.1111/j.1600-051X.2008.01272.x.

7. Ella B, Sédarat C, Noble RC, Normand E, Lauverjat Y, Siberchicot $\mathrm{F}$, et al. Vascular connections of the lateral wall of ed that the prevalence of sinus septa was $58 \%$, and Neugebauer et al. ${ }^{21}$ reported that it was $47 \%$. Lana et al. ${ }^{22}$ stated that the prevalence of antral septa was $44.4 \%$. The data in these reports may be due to the use of CBCT to identify the septa. Lana et al. ${ }^{22}$ also found that the prevalence of mucosal thickening was $54.8 \%(\leq 3 \mathrm{~mm})$ and $62.6 \%(\geq 3 \mathrm{~mm})$ with CBCT. The prevalence of sinus membrane thickening was $57.4 \%$ in our present study. However, we evaluated only the existence of sinus mucosa thickening, and the thickness was not measured. The prevalence of thickening reported by Lana et al. ${ }^{22}$ was consistent with those of the present study.

\section{Conclusion}

We conclude that preoperative imaging with CBCT seems to be helpful for assessing the location of the PSAA and the maxillary sinus morphology, which may be used to adjust the surgical treatment plan to yield more successful dental implant treatments. the sinus: surgical effect in sinus augmentation. Int J Oral Maxillofac Implants. 2008 Nov-Dec;23(6):1047-52.

8. van den Bergh JP, ten Bruggenkate CM, Disch FJ, Tuinzing DB. Anatomical aspects of sinus floor elevations. Clin Oral Implants Res. 2000 Jun;11(3):256-65.

9. Garg AK. Augmentation grafting of the maxillary sinus for placement of implants: anatomy, physiology, and procedures. Implant Dent. 1999;8(1):36-46.

10. Lorenzoni DC, Bolognese AM, Garib DG, Guedes FR, Sant'anna EF. Cone-beam computed tomography and radiographs in dentistry: aspects related to radiation dose. Int J Dent. 2012;2012:813768. DOI: 10.1155/2012/813768. Epub 2012 Apr 4

11. Ludlow JB, Ivanovic M. Comparative dosimetry of dental CBCT devices and 64-slice CT for oral and maxillofacial radiology. Oral Surg Oral Med Oral Pathol Oral Radiol Endod. 2008 Jul;106(1):106-14.

12. Valentin J. The 2007 Recommendations of the International Commission on Radiological Protection. Publication 103. Ann ICRP. 2007;37:1-34.

13. Güncü GN, Yildirim YD, Wang HL, Tözüm TF. Location of posterior superior alveolar artery and evaluation of maxillary sinus anatomy with computerized tomography: a clinical study. Clin Oral Implants Res. 2011 Oct;22(10):1164-7. DOI: 10.1111/j.1600-0501.2010.02071.x. Epub 2011 Jan 18. 
14. Elian N, Wallace S, Cho SC, Jalbout ZN, Froum S. Distribution of the maxillary artery as it relates to sinus floor augmentation. Int J Oral Maxillofac Implants. 2005 SepOct;20(5):784-7.

15. Mardinger O, Abba M, Hirshberg A, Schwartz-Arad D. Prevalence, diameter and course of the maxillary intraosseous vascular canal with relation to sinus augmentation procedure: a radiographic study. Int J Oral Maxillofac Surg. 2007 Aug;36(8):735-8. Epub 2007 Jul 12.

16. Kim JH, Ryu JS, Kim KD, Hwang SH, Moon HS. A radiographic study of the posterior superior alveolar artery. Implant Dent. 2011 Aug;20(4):306-10.

17. Chanavaz M. Sinus grafting related to implantology. Statistical analysis of 15 years of surgical experience (1979-1994). J Oral Implantol. 1996;22(2):119-30.

18. Krennmair G, Ulm C, Lugmayr H. Maxillary sinus septa: incidence, morphology and clinical implications. J Craniomaxillofac Surg. 1997 Oct;25(5):261-5.
19. Kim MJ, Jung UW, Kim CS, Kim KD, Choi SH, Kim CK, et al. Maxillary sinus septa: prevalence, height, location, and morphology. A reformatted computed tomography scans analysis. J Periodontol. 2006 May;77(5):903-8.

20. Orhan K, Kusakci Seker B, Aksoy S, Bayindir H, Berberoğlu A, Seker E. Cone beam CT evaluation of maxillary sinus septa prevalence, height, location and morphology in children and an adult population. Med Princ Pract. 2013;22(1):47-53. DOI: 10.1159/000339849. Epub 2012 Jul 24.

21. Neugebauer J, Ritter L, Mischkowski RA, Dreiseidler T, Scherer P, Ketterle M, et al. Evaluation of maxillary sinus anatomy by cone-beam CT prior to sinus floor elevation. Int J Oral Maxillofac Implants. 2010 Mar-Apr;25(2):258-65.

22. Lana JP, Carneiro PM, Machado VC, Souza PE, Manzi FR, Horta MC. Anatomic variations and lesions of the maxillary sinus detected in cone beam computed tomography for dental implants. Clin Oral Implants Res. 2012 Dec;23(12):1398-403. DOI: 10.1111/j.1600-0501.2011.02321.x. Epub 2011 Oct 3. 